\title{
Comparison of dexmedetomidine versus esmolol (Intravenously) in reduction of cardiovascular responses to intubation during induction of general anesthesia- A randomised clinical trial
}

\author{
Shivanand Y. Hulakund ${ }^{1}$, Archana R. Endigeri ${ }^{2, *}$, Navya C. N. ${ }^{3}$, Prakashappa D. S. ${ }^{4}$ \\ ${ }^{1}$ Professor, ${ }^{2}$ Assistant Professor, ${ }^{3}$ Junior Resident, ${ }^{4}$ Professor \& HOD, Dept. of Anesthesiology, S. N. Medical College, H.S.K. \\ Hospital \& Research Centre, Bagalkot, Navanagar, Karnataka, India \\ *Corresponding Author: \\ Email: archanaendigeri86@gmail.com
}

Received: $16^{\text {th }}$ January, 2017

Accepted: $21^{\text {st }}$ May, 2017

\begin{abstract}
Introduction and Aim: The cardiovascular changes to airway manipulation like tachycardia and hypertension occur secondary to catecholamine secretion. These changes make less effects on normal patients but can be hazardous in cardiac compromised patients. Various pharmacological measures are tried to lessen these ill effects. As a result we made an effort to compare the usefulness of two drugs, highly specific $\alpha 2$ agonist Dexmedetomidine at a dosage of $1 \mu \mathrm{g} / \mathrm{kg}$ versus Esmolol $1 \mathrm{mg} / \mathrm{kg}$; in reducing these effects during induction of G.A.

Materials and Methods: In this randomized clinical trial 102 patients, of age group 18-65 years and American Society of Anesthesiology classification I/ II, undergoing various surgeries under G.A. requiring intubation were distributed into 2 groups of 51 patients each. Group D patients were given Dexmeditomedine $1 \mu \mathrm{g} / \mathrm{kg}$ in diluted form over a time period of 10 minutes and Group E patients were given Esmolol $1 \mathrm{mg} / \mathrm{kg}$ diluted to $10 \mathrm{ml}$ and given over $1 \mathrm{~min}$.Induction of anesthesia was done with volatile agent sevoflurane. Maintenance was done with $\mathrm{O} 2$ and N2O 30:60 along with vecuronium. Monitoring was done and hemodynamic parameters were recorded at particular intervals during laryngoscopy and intubation of trachea.

Results: All observations were expressed as mean and standard deviation. Based on statistical analysis the Baseline heart rate, and baseline mean arterial pressure were comparable in both the groups. The decrease in mean HR observed at, 3,5 and 10minutes after intubation in Group D was statistically highly significant compared to mean HR in group E (p<0.000). (table 2). The mean fall in SBP in group D at 1, 3, 5 and 10 minutes after intubation was statistically highly significant $(\mathrm{p}=0.000)$ compared to the Esmolol group E The fall in mean DBP value at 1,3, 5 and 10 minutes of intubation were statistically highly significant $(\mathrm{p}=0.000)$ in group D compared to the latter group. The mean basal MAP, $2 \mathrm{~min}$ after drug administration and 1min after induction are comparable in both groups $(p>0.05)$. The fall in mean MAP values in group $D$ at $1,3,5$ and 10 minutes of intubation were statistically highly significant $(\mathrm{p}<0.0000001)$ compared to group E. $1 \mathrm{~min}$ after induction fall in mean RPP value in D group is statistically higher than in E Group $(\mathrm{P}=0.0243)$. We also noticed hypotension in 5 patients and a fall in heart rate in 3 patients of study group in group D which did not need any medication. However no patients in the latter group had these side effects, we attribute this to the lesser dosage of esmolol used.

Conclusion: This study shows that dexmeditomedine $1 \mu \mathrm{g} / \mathrm{kg}$ is better than esmolol $1 \mathrm{mg} / \mathrm{kg}$ for lessening the stress response to airway manipulation
\end{abstract}

Keywords: Dexmedetomidine, Endotracheal intubation, Esmolol Laryngoscopy, Hemodynamic responses.

\section{Introduction}

Pressure response to laryngoscopy and intubation is a well-known factor which may present in various forms, for instance autonomic disturbance, increase in ocular and cranial pressure thereby causing tachycardia, hypertension, arrhythmias etc. ${ }^{1}$ These fluctuations are found to be due to sympathetic stimulation ${ }^{2}$ secondary to increased catecholamine activity. ${ }^{3}$ Various factors are found to increase the intensity of these changes such as time taken for laryngoscopy, insertion of orotracheal tube , the variety of blade 4 the agent used to anesthetize and the adequacy of anesthesia. These changes are maximum at one minute after intubation and persist for ten minutes. Although well tolerated by normal healthy patients, it may result in hazards like myocardial ischemia, sudden failure of left ventricular chamber of heart, dysrhythmias, pulmonary edema and CVA in individuals in whom multiple organs are suffering from severe congestion due to fluid that is inadequately circulated by the failing heart. ${ }^{5,7}$,end organ decompensation $\}$. An increase in pulse rate together with elevation in systolic BP increases the rate pressure product, thus compromising myocardial contractility and oxygen supply. ${ }^{4}$

Variety of pretreatments ranging from topical anesthesia of larynx to administration of several classes of drugs like nitroglycerine, $\beta$ receptor blocking agents and opioids have been identified. Each technique has its own advantages as well as disadvantages. Multimodal therapy is in practice to attenuate this response. ${ }^{5}$ Dexmedetomidine a selective $\alpha 2$ agonist provides multimodal features like sedation, hypnosis, analgesia and sympatholysis. It also decreases levels of catecholamines during surgery and maintains intra operative hemodynamics. Esmolol is a highly selective $\beta 1$ blocking drug which is used mainly for peri 
operative control of BP and hemodynamic stability. Since both, an age old established $\beta 1$ blocker esmolol and highly $\alpha_{2}$ specific agonist dexmedetomidine act upon sympathetic system through different means we chose to compare and find out which of these drugs is more helpful in lessening the stress response.

\section{Materials and Methods}

After obtaining the institutional scientific and ethical committee approval and consent of patient and patients relatives, 102 patients belonging to age group of 18-65 years with ASA physical status I/II undergoing different operative procedures requiring general anesthesia, were taken in the study whereas patients with allergy or contraindications to the study drug, patients with anticipated difficult airway, pregnant patients or lactating patients, morbidly obese patients, patients suffering from cardiac illness, diabetes, patients with heart rate $<60 \mathrm{bpm}$ and systolic blood pressure < $100 \mathrm{mmHg}$ were excluded from our study.

All of the 102 patients were distributed into two groups with 51 patients based on simple randomized technique to receive the study drugs. Group DDexmedetomidine group $(\mathrm{n}=51)$ : received injection Dexmedetomidine $(1 \mu \mathrm{g} / \mathrm{kg})$ diluted to $10 \mathrm{ml}$ with normal saline intravenously over $10 \mathrm{~min}$ using a syringe pump. Group E - Esmolol group $(\mathrm{n}=51)$ : received Inj Esmolol $1 \mathrm{mg} / \mathrm{kg}$ diluted to $10 \mathrm{ml}$ with normal saline over 60 seconds . Once the patient arrived into the operation theatre, a dragger multi parameter monitor was attached and intravenous cannula preferably of 20 $\mathrm{G}$ was inserted and connected to ringer lactate fluid. 5 minutes after the patient settled in the theatre, baseline of all the hemodynamic and respiratory parameters were recorded. (heart rate and rhythm, blood pressure i.e systolic, diastolic, and mean arterial pressure, $\mathrm{O}_{2}$ saturation, and ECG). After that all the patients were given premedication with Glycopyrrolate $0.005 \mathrm{mg} / \mathrm{kg}$, to decrease the oral secretions occurring either due to drugs or airway manipulations during intubation; midazolam $0.03 \mathrm{mg} / \mathrm{kg}$ and fentanyl $2 \mu \mathrm{g} / \mathrm{kg}$. The study drugs were given as mentioned below 3 minutes prior to intubation.

Group D received dexmedetomidine $1 \mu \mathrm{g} / \mathrm{kg}$ body weight diluted in $10 \mathrm{ml}$ normal saline intravenously over $10 \mathrm{~min}$, using syringe pump (Drug preparation: $100 \mu \mathrm{g}$ of dexmedetomidine $(1 \mathrm{ml})$ was added to $9.0 \mathrm{ml}$ of normal saline and made to $10 \mathrm{ml}$ with each $\mathrm{ml}$ containing $10 \mu \mathrm{g}$ of dexmedetomidine). Group $\mathrm{E}$ received inj. Esmolol $1 \mathrm{mg} / \mathrm{kg}$ body weight diluted to $10 \mathrm{ml}$ over 60 seconds. This study was not blinded as the rate of drug administration varies.

Preoxygenation was done for 3 mins, patients were induced with sevoflurane (adjusted till loss of verbal response). Orotracheal intubation was facilitated with IV Vecuronium bromide $0.1 \mathrm{mg} / \mathrm{kg}$ three minutes prior to laryngoscopy and intubation. Intubation was performed using appropriate sized Macintosh blade lasting for not more than 15 seconds and after confirmation of bilateral equal air entry, the endotracheal tube was fixed. If time for laryngoscopy and intubation exceeded 15 seconds or intubation required more than 2 attempts such patients were excluded from the study. Anesthesia was maintained with oxygen and nitrous oxide, in the ratio of 30:60, sevoflurane (end tidal 1.5\%) and incremental doses of vecuronium bromide. No surgical or any other stimulus was applied during 10 minutes of study period. At the end of the procedure patients were reversed with neostigmine $0.05 \mathrm{mg} / \mathrm{kg}$ and glycopyrrolate $0.02 \mathrm{mg} / \mathrm{kg}$.

Heart rate, systolic blood pressure (SBP), diastolic blood pressure(DBP),mean arterial pressure(MAP) and rate pressure product(RPP) were measured at the following time periods base line before giving study drug, 2 minutes after study drug, 1 min after induction, 1 minute, 2 minutes, 3 minutes, 5 minutes after intubation respectively.

Side effects like fall in B.P, tachycardia, bradycardia or any type of dysrhythmias were also noted. Statistical analysis: The statistical software namely Microsoft excel, SPSS version 20, Open Epi version 2 were used for analysis of data and to generate graphs, tables etc Sample size was calculated with $80 \%$ of power analysis and 95\% as confidence level and $10 \%$ as the absolute error. Demographic data of the patients were expressed in the form of mean \pm standard deviation. The statistical data were analysed by paired student's $t$-test for intra-group variations of values and unpaired t-test for inter-group variations. Values were considered important when $\mathrm{p}<0.05$.

\section{Results and Discussion}

The groups were comparable with respect to age, weight, ASA physical status, gender as well as the type of surgeries underwent (table1)

Table 1: Demographic profile

\begin{tabular}{|l|c|c|}
\hline & Group D & Group E \\
\hline Age $($ Mean \pm S.D) & $31.902 \pm 10.1296$ & $33.039 \pm 11.14$ \\
\hline Male:Female & $33.3: 66.7$ & $33.3: 66.7$ \\
\hline Weight(KG) & $56.667 \pm 8.799$ & $56.667 \pm 8.799$ \\
\hline Surgeries & & \\
\hline Lap appendicetomy & 38 & 40 \\
\hline Lap cholecystectomy & 06 & 04 \\
\hline
\end{tabular}




\begin{tabular}{|l|l|l|}
\hline Thyroidectomy & 07 & 06 \\
\hline Miscellaneous(Cystogastrotomy) & & 01 \\
\hline
\end{tabular}

Baseline heart rate, mean arterial pressure were comparable in both the groups The mean HR decrease observed at 3,5 and 10minutes after intubation in Group D was statistically highly significant compared to mean HR in group $\mathrm{E}(\mathrm{p}<0.000)$. (table 2)

Table 2: Comparison of mean heart rate (bpm) changes in response to laryngoscopy and intubation between group $D$ and group $E$

\begin{tabular}{|l|c|c|c|c|}
\hline \multicolumn{1}{|c|}{ Time } & Group D & Group E & p-value & t-value \\
\hline Baseline & $5.78 \pm 11.85$ & $89.64 \pm 10.54$ & $0.085(\mathrm{NS})$ & 1.7354 \\
\hline 2 min after drug & $72.37 \pm 12.89$ & $76.15 \pm 8.81$ & $0.086(\mathrm{NS})$ & 1.7304 \\
\hline 1 min after induction & $71.01 \pm 11.19$ & $75.03 \pm 8.87$ & $0.47(\mathrm{~S})$ & 20.103 \\
\hline 1 min after intubation & $84.03 \pm 10.83$ & $97.76 \pm 10.40$ & $0.000(\mathrm{HS})$ & 6.5239 \\
\hline 3 min after intubation & $78 . .07 \pm 10.53$ & $91.09 \pm 9.26$ & $0.000(\mathrm{HS})$ & 6.6270 \\
\hline 5 min after intubation & $74.52 \pm 11.04$ & $85.98 \pm 8.91$ & $0.000(\mathrm{HS})$ & 5.7607 \\
\hline 10 min after intubation & $72.70 \pm 10.02$ & $82.09 \pm 9.00$ & $0.000(\mathrm{HS})$ & 4.9769 \\
\hline
\end{tabular}

The mean fall in SBP in group D at 1, 3,5 and 10 minutes after intubation was statistically highly significant $(\mathrm{p}=0.000)$ compared to the Esmolol group $\mathrm{E}$ The fall in mean DBP value at 1,3,5 and 10 minutes of intubation were statistically highly significant $(\mathrm{p}=0.000)$ in group $\mathrm{D}$ compared to the latter group.

The mean basal MAP, 2 min after drug administration and $1 \mathrm{~min}$ after induction are comparable in both groups (p>0.05).The fall in mean MAP values in group D at 1, 3,5 and 10 minutes of intubation were statistically highly significant $(\mathrm{p}<0.0000001)$ compared to group $\mathrm{E}$.

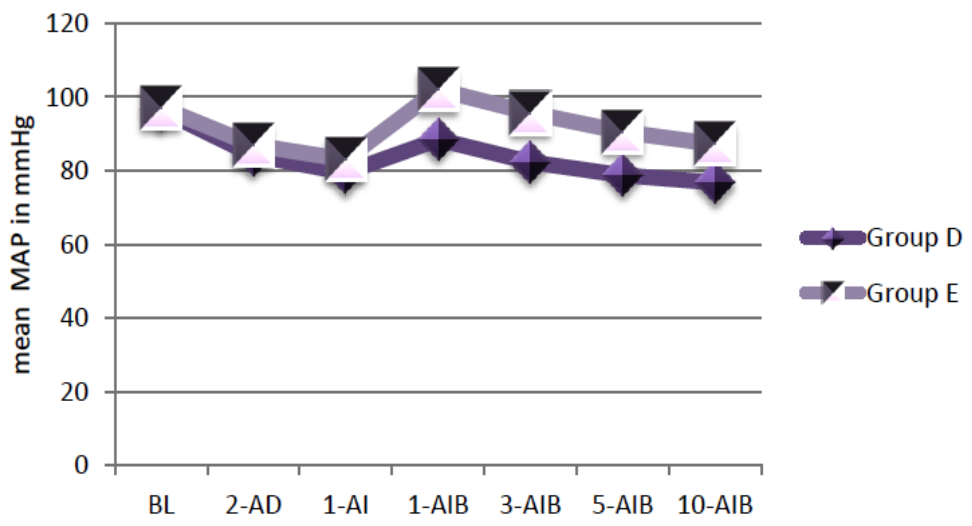

Fig. 1: Mean of MAP (mmHg) changes in response to laryngoscopy and intubation between group $D$ and group $\mathbf{E}$

1 min after induction fall in mean RPP value in group $\mathrm{D}$ is statistically higher than in group $\mathrm{E}(\mathrm{P}=0.0243)$. The fall in mean RPP values in at 1, 3, 5 and 10 minutes of intubation were statistically highly significant $(\mathrm{p}<0.0000001)$ compared to group E. [RPP calculated by formula (SBPX HR)/1000)] 


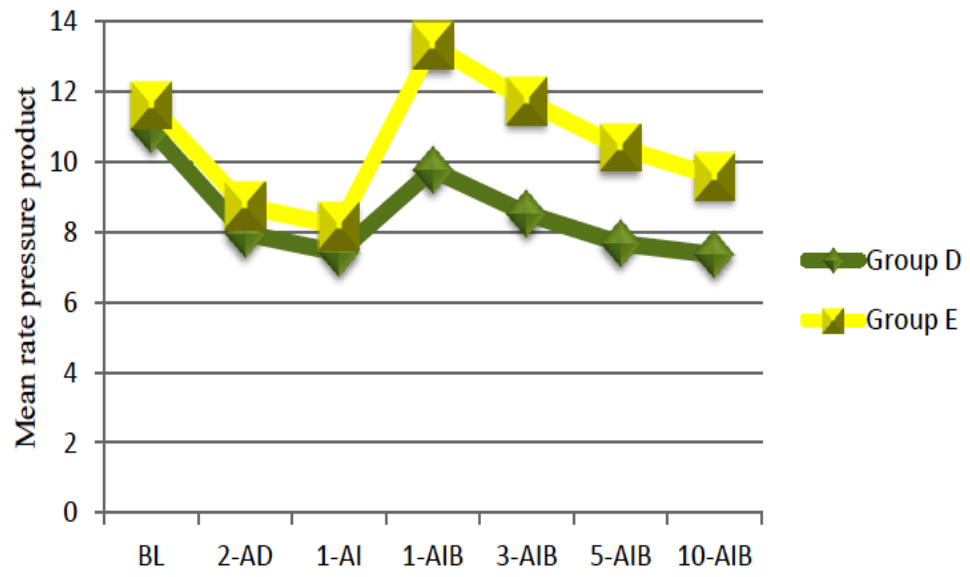

Fig. 2: Mean rate pressure product changes in response to laryngoscopy and intubation between group $D$ and group $\mathbf{E}$

(Rate pressure product (RPP) is a term used in cardiology, as well as exercise physiology, to measure the workload or oxygen demand of the myocardium and reflects hemodynamic stress.)

Side effects/Complications: We noticed $10 \%$ incidence of hypotension and a fall in heart rate in $6 \%$ of study group in group D which did not require any intervention. However none of the patients in group $\mathrm{E}$ had these side effects.

\section{Discussion}

During the induction of general anesthesia insertion of laryngoscope and insertion of tracheal tube play a critical role as they provoke transient but marked sympathetic response which could be detrimental in patients of cardiac illness. ${ }^{5-7}$ This in turn results in increase in blood pressure and heart rate and hence the rate pressure product (RPP). A high RPP indicates a potential danger of myocardial ischaemia. As these adverse hemodynamic effects are controlled through sympathetic nervous system and therefore may be suppressed by supplementing drugs which blocks adrenergic receptors. Many adjuvants like $\beta$-blockers, opioids, calcium channel blockers, $\alpha 2$ agonist drugs and esmolol or combinations have been tried in various studies, for blunting of hemodynamic responses, but if these adjuvants were used in higher than normal doses it had led to increased incidence of side effects.

Rathore $\mathrm{A}$ et $\mathrm{al}^{24}$ study came to a conclusion that esmolol is useful in attenuating the rise in mean pulse rate to airway manipulation with all doses like $(50,100$, $150 \mathrm{mg} / \mathrm{kg}$ ) but fall in BP was significant only with higher dose $(p=0.000)$.The RPP reduced with higher doses of the drug used mainly at $150 \mathrm{mg}$ ) but was associated with significant adverse effects (hypotension and bradycardia)

Bensky and colleagues ${ }^{22}$ suggested that small doses of Esmolol $(0.2-0.4 \mathrm{mg} / \mathrm{kg})$ may reduce the rise in HR and BP resulting from airway stimulation. Singhal et $\mathrm{al}^{19}$ found that when esmolol $1.5 \mathrm{mg} / \mathrm{kg}$ was administered $3 \mathrm{~min}$ prior intubation, increase in SBP and RPP was statistically not significant $p>0.05$. In view of above study we employed administration of esmolol 3 min prior intubation.
Based on the above studies low doses of esmolol like $0.2 \mathrm{mg}-0.4 \mathrm{mg}$ are also effective to reduce heart rate and blood pressure as concluded by Bensky et al and based on the study of Rathore et al all doses like 50mg, $100 \mathrm{mg}, 200 \mathrm{mg}$ were effective but more effective with higher doses but higher doses are also associated with adverse effects. This made us to proceed with a dose of esmolol $1 \mathrm{mg} / \mathrm{kg}$.

Sharma et $\mathrm{al}^{23}$ reported that the increase in MAP was not statistically significant after intubation (P> 0.05 ) with esmolol $100 \mathrm{mg}$, the arterial pressures were comparable to basal values and they noticed a profound fall in MAP ( $\mathrm{P}<0.001)$ with esmolol $200 \mathrm{mg}$. The probable reason for not having achieved a better response even with $100 \mathrm{mg}$ Esmolol is that they conducted their study on treated hypertensive patients.

The purpose of our study was to know the usefulness of Dexmedetomidine at a dose of $1 \mu \mathrm{g} / \mathrm{kg}$ and Esmolol at a dose of $1 \mathrm{mg} / \mathrm{kg}$ in lessening the hemodynamic response to laryngoscopy and endotracheal intubation. In our study dexmedet omidine was diluted in normal saline and given over 10 minutes using syringe pump to prevent transient rise in B.P. and HR that occur due to peripheral $\alpha-2$ adrenoceptors stimulation of smooth vessels in the vessels. The administration of dexmedetomidine as $10 \mathrm{ml}$ in the present study is similar to the administration by Scheinin et $\mathrm{al}^{17}$ and the timing of administration of dexmedetomidine was chosen from the pharmacokinetic profile (distribution $\mathrm{t} 1 / 2=6 \mathrm{~min}$ ).

We have induced the patients with sevoflurane rather than propofol as the fall in BP associated with propofol is more profound $10-40 \% .^{20,21}$ 
Jaakola and colleagues ${ }^{25}$ noted that after insertion of endotracheal tube the maximum heart rate was $18 \%$ less $(\mathrm{p}=0.036)$ in group $\mathrm{D}$ compared to placebo group. Within 10 min after intubation maximum systolic and diastolic pressures were also significantly $(\mathrm{p}=0.013$ and $\mathrm{p}=0.020$ ) smaller in dexmedetomidine group.

In our study, the fall in HR was statistically significant $(\mathrm{p}<0.05)$ at $1 \mathrm{~min}$ after induction of general anesthesia and statistically highly significant ( $\mathrm{p}$ $<0.0000001)$ after intubation in group D The fall in MAP and RPP was comparable in both the groups before intubation $(\mathrm{P}>0.05)$, but we found statistically highly significant fall in MAP in group D $(p<0.0000001)$ than in group E. Hence dexmedetomidine decreases the cardiac energy requirements more effectively than esmolol at the above mentioned dosage.

Our study also noted similar finding that esmolol reduced the rise in $\mathrm{HR}$ and $\mathrm{BP}$ and the reduction was higher compared to study conducted by Bensky and colleagues $^{22}$ as we chose a higher dose. In our study we found a significant but a lesser rise in arterial pressures than the study conducted by Rathore A et al, ${ }^{24}$ probably due to concomitant use of fentanyl which itself is a proven attenuator of stress response. But we do not consider it as a confounding factor as it was used in both the study groups.

We have found a greater fall in the HR, SBP, and DBP than Jaakola's study ${ }^{25}$ due to the greater dose of dexmedetomidine used Our results coincide with study conducted by Keniya et $\mathrm{al}^{26}$ who found a significant fall in $\mathrm{HR}$ and $\mathrm{BP}$ with use of $1 \mu \mathrm{g} / \mathrm{kg}$ dexmedetomidine $(p=0.000)$. Yavascaoglu ${ }^{27}$ found that the amount of reduction in HR in dexmedetomidine group $(0.5 \mathrm{mg} / \mathrm{kg})$ was higher than esmolol group $(0.5 \mathrm{mg} / \mathrm{kg})$ $(\mathrm{p}=0.046) . \mathrm{MAP}$ at $1 \mathrm{~min}$ after intubation in dexmedetomidine group was significantly less than that in esmolol group ( $\mathrm{p}=0.012$ and $\mathrm{p}=0.005$ respectively). Our study shows highly significant difference probably due to higher doses of study drugs used.

We noticed $10 \%$ incidence of hypotension and a fall in heart rate in $6 \%$ of study group in group D which did not require any intervention. However none of the patients in group $\mathrm{E}$ had these side effects, we attribute this to the lower dose of esmolol used.

Unlike other studies we have used fentanyl in our study which probably led to better attenuation even with small dose of esmolol.

\section{Conclusion}

Our study lead to the conclusion that Dexmedetomidine $1 \mu \mathrm{g} / \mathrm{kg}$ was more effective in attenuating the pressure response to laryngoscopy and intubation when compared to esmolol $1 \mathrm{mg} / \mathrm{kg}$.

\section{References}

1. Reid, Brace Irritation of respiratory tract and its reflex effect on heart surgeries. Gynaecology and Obstretics 1940;70:157.

2. King BD, Harris L, Greifenstein F, Elder J, Dripps RD. Reflex circulatory responses to direct laryngoscopy and intubation under general anesthesia.

Anesthesiology 1951;12:556-66.

3. Kayhan Z, Aldemir D, Metler H, Ogus E. Which is responsible for the hemodynamic response due to laryngoscopy and endotracheal intubation? Catecholamines, vasopressin or angiotensin? European journal of anesthesiology 2005;22:780-5.

4. Takashima Noda K. Cardiovascular responses to endotracheal intubation. Anaesth Analg 1964;43:201.

5. Prys-Roberts C, Green LT, Meloche R, Foex P. Studies of anesthesia in relation to hypertension II. Hemodynamic consequences of induction and endotracheal intubation. Br J Anesth 1971;43:531-47.

6. Prys Roberts C. Anesthesia and hypertension. Br J Anesth 1984; 56:711-24.

7. Fox EJ, Sklar GS, Hill CH Var V, King BD. Complications related to the pressor response to endotracheal intubation Anaesthesiology. 1977;47:5245.

8. Ronald D Miller. Miller's Anesthesia volume 2 Seventh edition 2010

9. Stoelting RK, Stephan F Dierdorf. Anaesthesia and coexisting disease 4th ed. 2002

10. Stoelting RK. Blood pressure and heart rate changes during short duration laryngoscopy for tracheal intubation influence of viscous or intravenous lignocaine Anaesthesia Analgesia 1978;57:197-9.

11. Stoelting RK. Circulatory changes during direct laryngoscopy and tracheal intubation Influence of duration of laryngoscopy with or without prior lignocaine Anaesthesiology 1977;47:381.

12. Martin DE, Rosenberg H, Aukburg SJ, Bartkowski RR, Edwards MW Jr, Greenhow DE, Klineburg PL. Low dose Fentanyl blunts circulatory responses to tracheal intubation. Anaesthesia Analgesia 1982;61(8):680-4.

13. Stoelting RK. Attenuation of blood pressure response to laryngoscopy and tracheal intubation with Sodium Nitroprusside Anesthesia Analgesia. 1979; 58:116-9.

14. Fuji Y, Tanaka H, Saitoh Y, Toyooka H. Effects of Calcium channel blockers on circulatory response to tracheal intubation in hypertensive patients Nicardipine vs Diltiazem. Canadian Journal of Anaesthesia 1995;42:785-8

15. Fossoulaki A, Kaniasis P. Intranasal administration of Nitroglycerine attenuates the pressor response to laryngoscopy and intubation of the trachea $\mathrm{Br} \mathrm{J}$ Anaesth 1983:55:49-52

16. Prys-Roberts C, Foex P, Biro GP. Studies of anaesthesia in relation to hypertension versus adrenergic $\beta$ receptor blockade $\mathrm{Br} \mathrm{J}$ Anaesth 1973:45:671-80.

17. Scheinin B, Lindgren L, Randell T, Scheinin H, Scheinin M. Dexmedetomidine attenuates sympathoadrenal response to tracheal intubation and reduces the need for thiopentone and perioperative fentanyl, Br J Anaesth 1992, 68:126-31.

18. Ebert JP, Pearson JD, Gelman S, Harris C, Bradley EL. Circulatory response to

19. laryngoscopy The comparative effects of Placebo, Fentanyl and Esmolol Canadian Journal of Anaesthesia. 1989;36:301-6. 
20. Singhal SK, Malhotra N, Kaur K, Dhaiya D. Efficacy of esmolol administration at different times in attenuatinghemodynamic response to tracheal intubation Indian Medsci2010; 64:468-75.

21. Joo HS, Perks WJ, sevoflurane versus propofol for anesthetic induction: a metaanalysis. A \& A 2000; 91:213-219.

22. Stoelting R.K,Hiller SC Physiology and Pharmacology in Anesthetic practice

23. Bensky KP, Donahue-Spencer L, Hertz GE, Anderson MT, James R. The dose related effects of bolus dose of esmolol and heart rate and blood pressure following laryngoscopy and tracheal intubation Anesth Analg J 2000 68:437-42.

24. Sharma S, Ghani A, Win N, Ahmad M. compariosn of two bolus doses of esmolol for attenuation of hemodynamic response to tracheal intubation, med $\mathbf{J}$ Malaysia1995;50:372-6.

25. Rathore A, Gupta HK, Tanwar GL, Rehman Hattenuation of pressure response to laryngoscopy and endotracheal intubation with different doses of esmolol Indian J. Anaessth.2002;46:449-52.

26. Jaakola ML, Ali-Malkkila T, Kanto J, Kallio A, Scheinin H, Scheinin M. Dexmeditomidine reduces intraocular pressure, intubation response and anesthetic requirement in patients undergoing ophthalmic surgery Br Journal of Anesth 1992,68:570-5.

27. Keniya VM, Ladi S, Naphade R. Dexmeditomidine attenuates sympathoadrenal response to tracheal intubation and reduces perioperative anesthetic requirement Indian J Anesth 2011 55:352-7.

28. Belgin Yavascaoglu, FN Kaya, M Bozkurt, S Korkmaz, M Baykara. A comparison of esmolol and dexmedetomidine for attenuation of intraocular pressure and hemodynamic responses to laryngoscopy and tracheal intubation Eur J Anesthesiol 2008. 25:508-524. 